\title{
First Evaluation on Structural Behavior of All FRP Bolted Built-up Columns
}

\author{
A. Adilardi and S. Russo
}

\begin{abstract}
The proposed study analyze the structural performances of built-up columns made by open FRP (fiber reinforced polymer) profiles. These open profiles are connected to each other and each column has two typologies of connection: the first guarantees the junction between the two channel- web and the second one assures the connection between the built-up-web and the external flanges. Specifically, the research verify the influence of the anisotropy of the material and the shear deformability as well as the interaction between local and global buckling on the overall bearing capacity of the assembled column. The analyzed case regards a built-up column made by four FRP channels made by pultrusion process and connected along the column with steel bolts. The study proposes both a numerical and experimental analysis. The comparison between these, aims to better fit particularly the influence of shear and to determine the local mechanisms of diffusion and the load's distribution through the bolted connection and the four FRP channels.
\end{abstract}

Index Terms - Local buckling, pultruded material, built-up column, steel-FRP interaction, shear effect.

\section{INTRODUCTION}

The proposed study analyzes the structural performances of built-up columns made by open pultruded FRP (fiber reinforced polymer) profiles between them connected through steel bolts. The research focused also on the interaction between local and global buckling with some deepening on the relation between FRP and steel material in the connections.

The research is in a current and previous frame related to the definition of the static and dynamic performance of the pultruded FRP elements already present in the technical recommendations [1], dedicated books and in literature [2], [3]. Also the topic related to the pultruded FRP connection has been very well studied, especially in presence of the beam-column connection [4].

Given that, these studies have supported also several applications by now widely used, as reinforcement,[5], emergency structures, [6], [7] or permanent ones, [8], [9], due, first of all, to the benefits related to the high value of strengths with low density and very high level of durability that characterize the pultruded FRP material. This material is used also for housing, pedestrian and vehicular bridges [10], [11], with first reference to the dissipative capacity - even if in presence of its elastic-brittle behavior [12], [13] - as well as in relation to the damage evaluation [14] and about the

Manuscript received April 15, 2014; revised June 18, 2014.

A. Adilardi is with Municipality of Prato, Italy.

S. Russo is with IUAV University of Venice, Dept of Design in Complex Environments Dorsoduro 2206, 30123 Venice, Italy (e-mail: russo@iuav.it). techniques disposable to understand the mechanical characteristics.

By the way, the proposed research take something as a starting point from the first works on the same item and analyzes now the shear and local effects on the buckling with first comparison with same built-up columns made by steel, at least from the structural design point of view.

The two typologies of all pultruded FRP built-up columns are characterized by a different dimensions of $C$ shape FRP elements and this study following other works dedicated to the same topic on a first global approach [15], [16].The study gives particularly care to the distribution of load through the four pultruded FRP channels.

\section{Mechanical Model And Tests Results}

Each column has two typologies of connection, the first named B1, guarantees the junction between the two channelweb, the second one, named $\mathrm{B} 2$, assures the connection between the built-up-web and the external flanges (Fig. 1). (a)

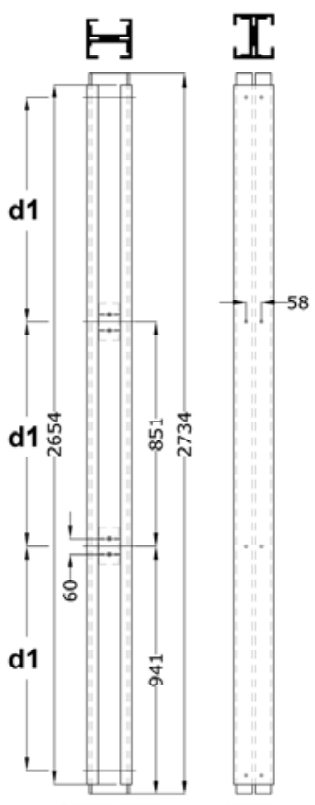

(b)

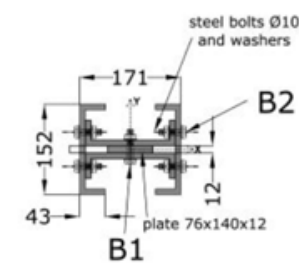

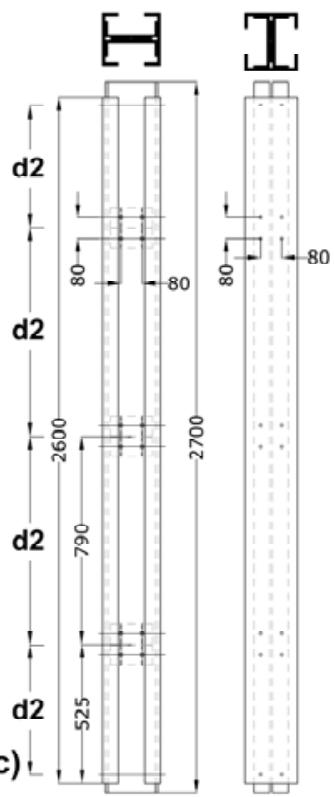

steel bolts $\emptyset 14$

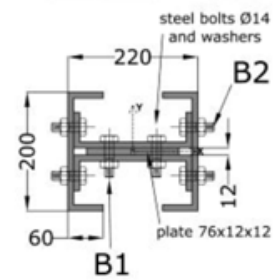

Fig. 1. Built-up columns, type $\mathrm{BC} 1$ detail (a-b) and type $\mathrm{BC} 2$ detail (c-d); measures in $\mathrm{mm}$.

The dimensions of the columns and the related 
cross-sections are reported in Fig. 1, while the mechanical features of the FRP pultruded material, also employed in the FE analysis, are indicated in Table I.

TABLE I: MECHANICAL CHARACTERISTICS OF PULTRUDED FRP MATERIAL MEAN VALUES

\begin{tabular}{|c|c|c|}
\hline Mechanical properties & Symbol & Value \\
\hline $\begin{array}{l}\text { Longitudinal tensile } \\
\text { strength }\end{array}$ & \multirow{3}{*}{$\begin{array}{l}\sigma_{X}=\sigma_{Y} \\
E_{Z=} E_{L}\end{array}$} & $350 \mathrm{MPa}$ \\
\hline Transversal tensile strength & & $70 \mathrm{MPa}$ \\
\hline $\begin{array}{l}\text { Longitudinal elastic } \\
\text { modulus }\end{array}$ & & $23 \mathrm{GPa}$ \\
\hline Transversal elastic modulus & \multirow{7}{*}{$\begin{array}{l}E_{X}=E_{Y}=E_{T} \\
G_{X Y}=G_{T} \\
G_{Z X}=G_{Z Y}=G_{L T} \\
v_{Z X}=v_{Z Y}=v_{L T} \\
v_{X Y}=v_{T} \\
\gamma \\
V_{\mathrm{f}}\end{array}$} & $8.5 \mathrm{GPa}$ \\
\hline Shear modulus & & $3.4 \mathrm{GPa}$ \\
\hline Shear modulus & & $3 \mathrm{GPa}$ \\
\hline Poisson's ratio & & 0.23 \\
\hline Poisson's ratio & & 0.09 \\
\hline Density & & $1750 \mathrm{~kg} / \mathrm{m}^{3}$ \\
\hline Fibres percentage & & $40 \%$ \\
\hline
\end{tabular}

\section{Distribution OF LOAD BetweEn CHANNElS THROUGH BOLTS}

From a general point of view, a first hypothesis about the progressive model of distribution of the load through the four pultruded FRP channels is proposed in Fig. 2.

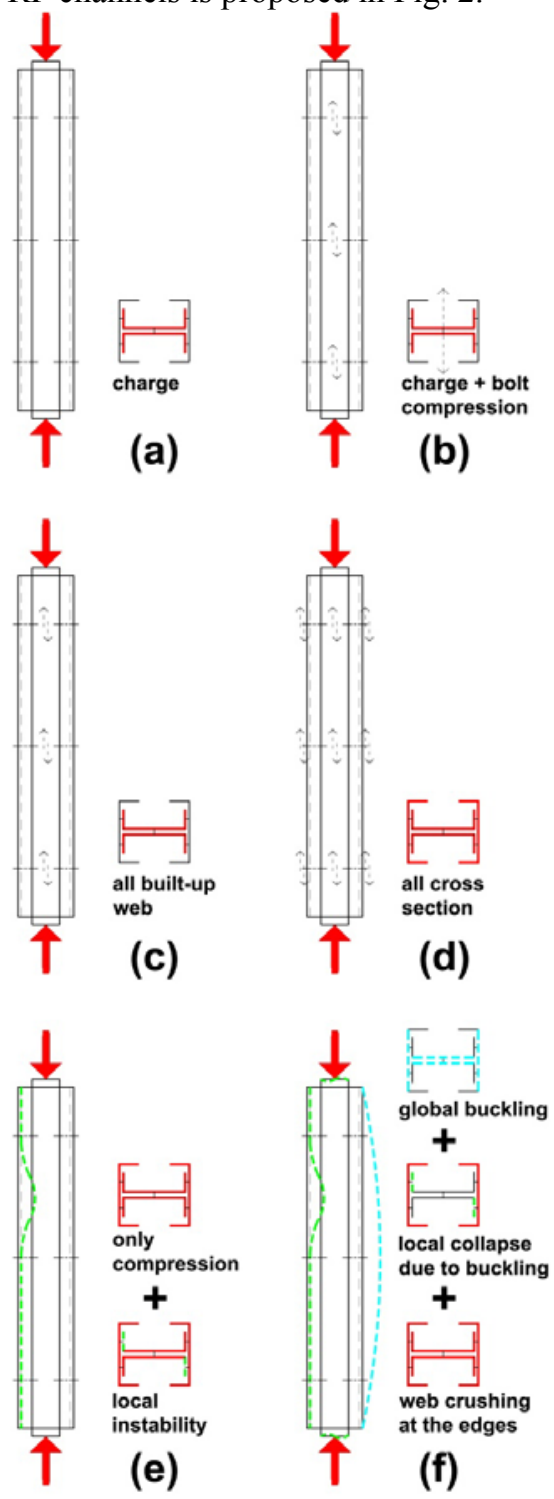

Fig. 2. Progressive model of the built-up column.
The described progressive charge of each built-up column gives prominence to the interaction between the two types of buckling, local and global [4]. Indeed in Fig. 3 are showed for example some cases of the different buckling interaction in presence of opens pultruded FRP shapes. The crisis of the two columns BC1 and BC2 are indicated in Fig. 4.
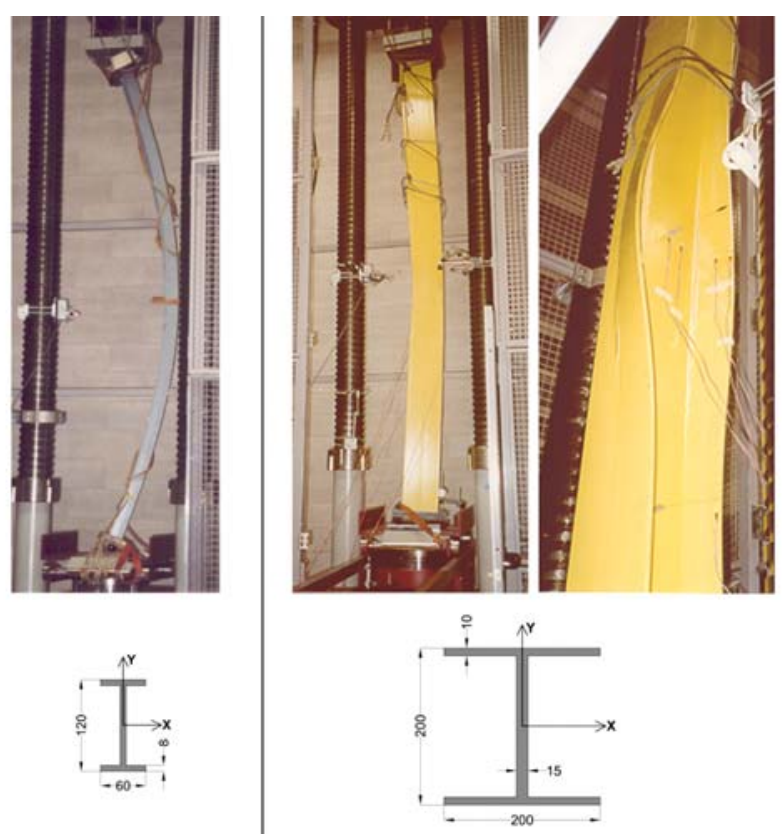

$120 \times 60 \times 8$

$\mathrm{L}=2500 \mathrm{~mm}$

Buckl. load $=11.3 \mathrm{kN}$

$200 \times 200 \times 15 \times 10$

$\mathrm{L}=\mathbf{2 8 0 0 \mathrm { mm }}$

Buckl. load $=492 \mathrm{kN}$

Fig. 3. Interaction between global and local buckling [4].
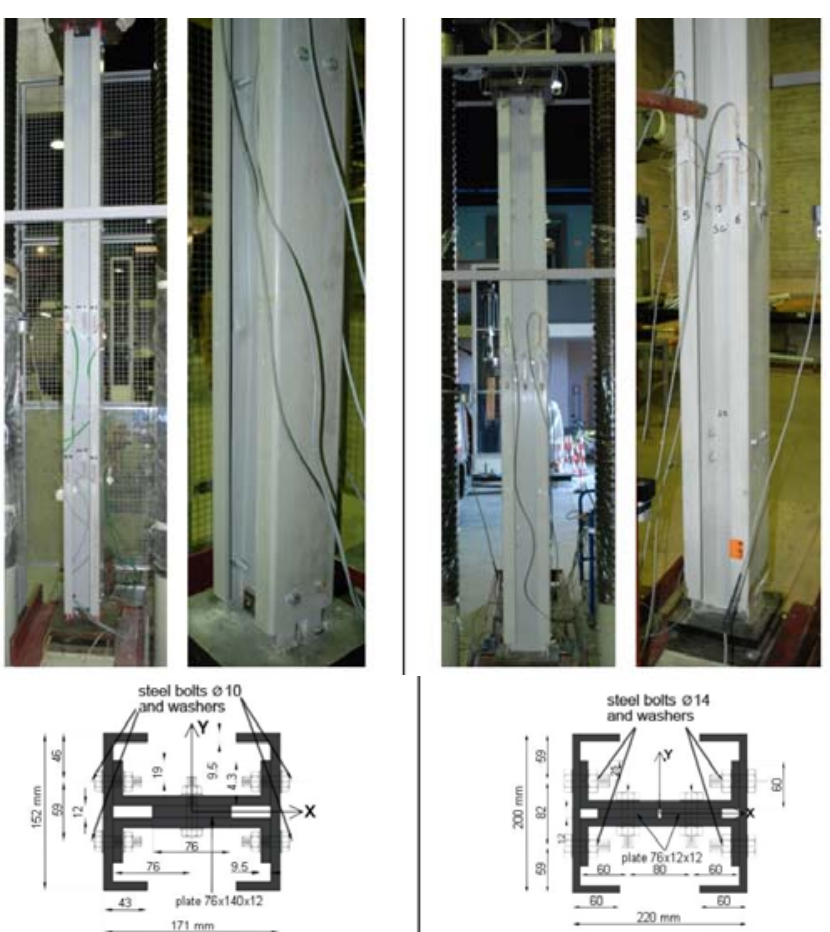

C1; Buckling load $=193 \mathrm{kN}$

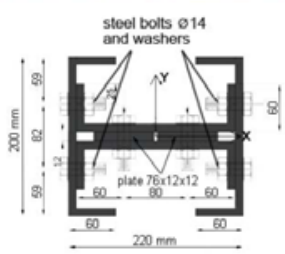

BC2; Buckling load $=688 \mathrm{kN}$

Fig. 4. Set up and collapse phases of built-up column BC1 and BC2

If we consider the equilibrium in the direction of the applied load, a simplified model could be proposed in agreement with the shortened of the built-up-web that onset the load transfer to the external flange. As showed in Fig. 5, the total load $N_{t o t}$ could be divided into $N_{1}$ and $N_{2}$ respectively applied to the 'built-up-web' 
and to the external flanges.

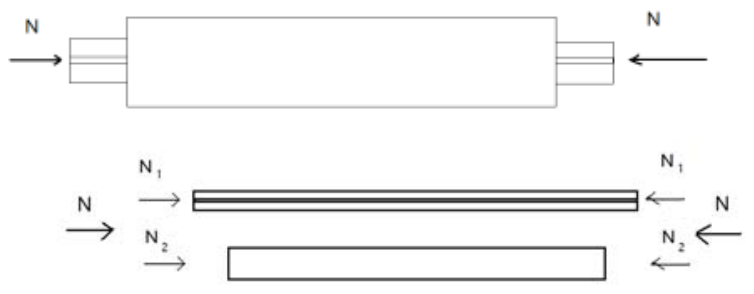

Fig. 5. Simplified model.

These following equations could be then proposed in function of the two areas involved that are the $A_{l}$ related to the built-up web and the $A_{2}$ as a sum of the two flanges:

$$
\begin{gathered}
N_{1}+N_{2}=N_{t o t} \\
2 \cdot N_{1} \cdot A_{1}+2 \cdot N_{2} \cdot A_{2}=N_{t o t}
\end{gathered}
$$

Starting from the assumptions indicate in (1) and (2) the following relations will be obtained:

$$
\begin{aligned}
& N_{1}=N_{t o t} \cdot \frac{N \cdot A_{1}}{\left(2 \cdot A_{1}+2 \cdot A_{2}\right)} \\
& N_{2}=N_{t o t} \cdot \frac{N \cdot A_{2}}{\left(2 \cdot A_{1}+2 \cdot A_{2}\right)}
\end{aligned}
$$

\begin{tabular}{|c|c|c|}
\hline Column & $V_{s d}-(k N)$ & $V_{m d}-(k N)$ \\
\hline \multicolumn{3}{|l|}{$B C 0$} \\
\hline Nmax exp & 24.16 & 27.54 \\
\hline Nmode I & 28.75 & 27.54 \\
\hline Nnon linear & 26.63 & 27.54 \\
\hline \multicolumn{3}{|l|}{$B C 1$} \\
\hline Nmax exp & / & 27.54 \\
\hline Nmode I & 37.50 & 27.54 \\
\hline Nnon linear & 37.38 & 27.54 \\
\hline \multicolumn{3}{|l|}{$B C 2$} \\
\hline Nmax exp & 42.42 & 42.85 \\
\hline Nmode I & 46.40 & 42.85 \\
\hline Nnon linear & 46.30 & 42.85 \\
\hline Channel C152 & $\operatorname{Ncr}(\mathrm{kN})=11.00$ & / \\
\hline Channel C200 & $\operatorname{Ncr}(k N)=17.00$ & 1 \\
\hline
\end{tabular}

TABLE II: VALUES OF BEARING CAPACITY IN BOLT CONNECTION

\section{CONCLUSION}

The model showed in Fig. 2 and in coherence with the one showed in Fig. 5 means that the rule of external connections is to transfer the load while the rule of the internal connection (along the length of each built up column) is to reduce the length related to the second order effects. Given that, in presence of the local bearing capacity in each bolted connection, we obtain [1]:

$$
V_{s d}=\frac{N_{2}}{n_{b o l t}}<V_{m d} \cdot \gamma_{f r p} \cdot D \cdot t
$$

where $V_{s d}$ coincide with the calculated strength due to bearing capacity, $N_{2}$ is the applied load to the flanges (Fig. 5), nbolt is the number of bolts, $V_{d m}$ is the declared strength from the producers assumed equal to $240 \mathrm{MPa}$. Then $\gamma_{\text {frp }}$ is the coefficient of the material assumed equal to $1.3[1]-[3], D$ and $t$ are respectively the diameter of the hole and the thickness of the pultruded FRP channel. About the intermediate connections between flanges and the built-up-web, the value of load in the bolt - that potentially is related to the local bearing capacity - will be compared with the critical load of a singular channel calculated through the Engesser approach [17], as following:

$$
N<N_{c r}
$$

where $N_{c r}$ represents therefore the critical load and $N$ is equal to $N_{2 / 2}$. Table II summarizes the calculated values of bearing capacities through the previously equations.

Based on the results showed in Table II, (5) is always satisfied for the column type $B C O$ and $B C 2$, while in presence of the column $B C 1$ the calculated value of bearing capacity exceeds the available strength. Besides, in presence of singular channel the $N_{c r}$ value is lower than the value in fact applied at each bolt.

\section{ACKNOWLEDGMENT}

For this research have been used scientific equipment acquired by the University IUAV of Venice within the project Iuav_lab, IUAV laboratories of innovation for architecture, the project is co-financed by the Veneto Region as part of the POR-CRO, the ERDF, 2007-2013, 1.1.1.

\section{REFERENCES}

[1] National Research Council of Italy, 205/2007, Guide for the Design and Construction of Structures made of FRP Pultruded Elements, Rome, October 2008.

[2] G. Boscato and S. Russo, "Free vibrations of pultruded FRP elements: Mechanical characterization, analysis, and applications," Journal of Composites for Construction, vol. 3, pp. 565-574, 2009.

[3] G. Boscato, J. T. Mottram, and S. Russo, "Dynamic response of a sheet pile of fiber reinforced polymer for waterfront barriers," Journal of Composites for Construction, vol.15, no. 6, p. 974, 2011.

[4] A. D. Tommaso and S. Russo, "Shape influence in buckling of GFRP pultruded columns," Mechanics of Composite Materials, vol. 39, no. 4, pp. 329-340, 2003.

[5] J. T. Mottram, "Further tests on beam -to column connections for pultruded frames: Web - cleated," Journal of Composites for Construction, vol. 3, no. 1, 1999.

[6] S. Russo, "On the monitoring of historic damaged by earthquake in L'Aquila," Structural Control and Health Monitoring, p. 1531, 2012.

[7] G. Boscato, M. Pizzolato, S. Russo, and A. Tralli, "Seismic behavior of a complex historical church in L'Aquila," International Journal of Architectural Heritage, vol. 4, no. 3, 2012

[8] G. Boscato, A. D. Cin, S. Russo, and F. Sciarretta, "Structural health monitoring of historic damaged churches," Advanced Materials Research, vol. 838-841, pp. 2071-2078, 2014.

[9] S. Russo, "Experimental and finite element analysis of a very large pultruded FRP structure subjected to free vibration," Composites Structures, vol. 94, pp. 1097-1105, 2012.

[10] S. Russo, "Performance of a PFRP structure covering a historic building struck by an earthquake," Advanced Composites in Construction 2011, pp. 51-57, 2011.

[11] S. Russo and A. Adilardi, "Innovative design approach to a GFRP pedestrian bridge: Structural aspects, engineering optimization and maintenance," in Proc. the Fifth International Conference on Bridge Maintenance, Safety and Management, Philadelphia (USA), pp. 2455-2459, 2010.

[12] G. Boscato and S. Russo, "On mechanical performance of different type of FRP beams as reinforcement of pedestrian bridge," in Proc. the Fourth Int. Conf. on Bridge Maintenance, Seoul, Korea, pp. 202-206, 2008.

[13] G. Boscato and S. Russo, "Free vibrations of a pultruded GFRP frame with different rotational stiffness of bolted joints," Mechanics of Composite Materials, vol. 48, no. 6, pp. 655-668, 2013. 
[14] G. Boscato and S. Russo, "Dissipative capacity of FRP spatial pultruded structure," Composite Structures, pp. 1-6, 2014.

[15] S. Russo, "Damage assessment of GFRP pultruded structural elements," Composite Structures, 2013.

[16] G. Boscato, C. Casalegno, S. Russo, and J. T. Mottram, "Buckling of GFRP pultruded built-up columns," Advanced Composites in Construction, pp. 178-189, 2013.

[17] G. Boscato, C. Casalegno, S. Russo, and J.T. Mottram, "Buckling of built-up columns of pultruded fiber-reinforced polymer c-sections," Journal of Composite for Construction, vol. 17, 2013

[18] S. P. Timoshenko and J. M. Gere, Theory of Elastic Stability, Mc Graw Hill, S. Ed., 1961.

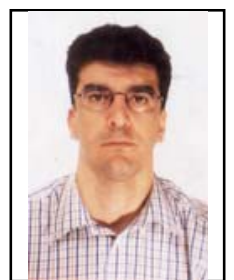

S. Russo was born in Bologna (Italy) on Febbruary 14 1962. He graduated summa cum laude in architecture at IUAV University in Venice earlier than the prescribed course duration, with a thesis entitled "Structural restoration of the former Refectory of Frari in Venice". He graduated in civil engineering at the University of Trieste, with a thesis entitled "Analysis and modeling of channels' re-establishment in the isle of Torcello". In 2001, he succeeded in the national competitive examination for the position of associate professor of Structural Civil Engineering, and IUAV University of Venice then appointed him in 2002. In 2007, he got the first book published in Italy on the structural use of thin fiber-reinforced composite pultruded members. He is an author of 158 scientific items. In 2006, he started collaborating to the editing of the National Research Council Technical Document (CNR DT) 2005/2007 on the structural use of thin fiber-reinforced composite pultruded members. Since 2009, he is an elected member of the Academic Senate of IUAV University of Venice. Since 2010, he is the director of the Laboratory of Strength of Materials at IUAV University of Venice. In 2008, he received an international award as the author of 'Best scientific paper'. Since 1998, he takes part in international cooperative scientific researches. 